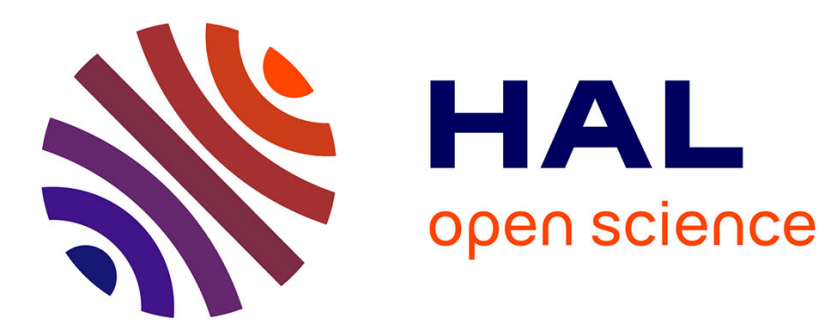

\title{
Sputtered Ag thin films with modified morphologies: Influence on wetting property
}

Perrine Dutheil, Anne-Lise Thomann, T Lecas, Pascal Brault, Marylène Vayer

\section{To cite this version:}

Perrine Dutheil, Anne-Lise Thomann, T Lecas, Pascal Brault, Marylène Vayer. Sputtered Ag thin films with modified morphologies: Influence on wetting property. Applied Surface Science, 2015, 347, pp.101-108. 10.1016/j.apsusc.2015.04.052 . hal-01149042

\section{HAL Id: hal-01149042 \\ https://hal.science/hal-01149042}

Submitted on 6 May 2015

HAL is a multi-disciplinary open access archive for the deposit and dissemination of scientific research documents, whether they are published or not. The documents may come from teaching and research institutions in France or abroad, or from public or private research centers.
L'archive ouverte pluridisciplinaire HAL, est destinée au dépôt et à la diffusion de documents scientifiques de niveau recherche, publiés ou non, émanant des établissements d'enseignement et de recherche français ou étrangers, des laboratoires publics ou privés. 
Sputtered Ag thin films with modified morphologies: influence on wetting property

P. Dutheil ${ }^{\text {a*}}$, A.L. Thomann ${ }^{\text {a }}$, T. Lecas ${ }^{\text {a }}$, P. Brault ${ }^{\text {a }}$, M.Vayer ${ }^{b}$

a GREMI, UMR 7344- Université D'Orléans, 14 rue d'Issoudun, BP 6744, Orléans 45067, France

${ }^{\mathrm{b}} \mathrm{CRMD}, 1 \mathrm{~b}$ rue de la Férollerie, 45071 Orléans, France.

*Corresponding author at: GREMI, 14 rue d'Issoudun, BP6744, 45067 Orléans cédex2, FRANCE Tel: +33238 4970 47, e-mail address : perrine.dutheil@ univ-orleans.fr

Abstract:

Silver thin films with thickness ranging from $3 \mathrm{~nm}$ to $33 \mathrm{~nm}$ were sputter deposited onto silicon wafers and tungsten layers. Those $\mathrm{W}$ layers were previously synthesized in the same DC magnetron sputter deposition system with various experimental conditions (argon pressure, target to substrate distance) in order to stabilize different surface morphologies. SEM observations and AFM images showed that the growth mode of Ag films is similar on $\mathrm{Si}$ substrates and on the smoothest $\mathrm{W}$ layers, whereas it is modified for rough $\mathrm{W}$ layers made of sharp grains. The effect of the W layer morphology on Ag film growth was clearly evidenced when the deposition took place at high temperature. It is seen that performing the deposition onto substrates of various morphologies allows to tailor the wetting property of the $\mathrm{Ag}$ deposit.

Keywords: Ag thin films, W under layer, surface morphology, wetting property

\section{Introduction}

It is well known that wetting properties of materials depend on their chemical nature and their roughness/morphology. The role of the surface roughness has widely been studied and it has been found to have opposite effects: increasing the roughness of a chemically hydrophobic surface will enhance its hydrophobicity, while increasing the roughness of a hydrophilic surface will further its hydrophilicity [1]. It has also been shown that surface state composed of superposition of two roughness patterns at different length scales, and fractal roughness may lead to superhydrophobicity, characterized by a contact angle higher than $150^{\circ}$ [2]. Studies have been conducted on the roughness scales that would promote superhydrophobicity $[3,4]$. It has been found that nano-roughness associated to micropatterns could promote this property, for instance by studying biological samples such as Lotus leaves [5]. This kind of multimodal roughness has been successfully obtained on various metal surfaces $[6,7]$. It is interesting to note that by properly texturing the surface, superhydrophobicity has been obtained on hydrophilic substrates, showing the major role played by the morphology on the wetting property [8].

Depending on the targeted application, hydrophobic or hydrophilic surfaces are requested. Hydrophilicity is preferred when strong interaction with aqueous media is necessary, like for example, antibacterial property or anti-fogging [9]. On hydrophilic surfaces the presence of a tightly adherent layer of water may help avoiding oil adsorption, 
like in anti-graffiti coatings [10]. Hydrophobicity and superhydrophobicity is associated to water repellency, anti-fouling, anti-adhesion and self-cleaning [11]. Usually for a surface to be self-cleaned a high static contact angle is not the only required parameter, a low sliding angle is also necessary, that means the contact angle hysteresis has to be low [9]. On this kind of surfaces, the droplets may roll in addition to slide, which facilitates removal of contaminant particles and waste, which are weakly link to the material [4].

However in some cases, a self-cleaning effect has been reported for superhydrophilic surfaces, like for $\mathrm{TiO}_{2}$-based compounds [12]. Self-cleaning property of $\mathrm{TiO}_{2}$ has been investigated by many authors and has been found to be also related to its photo-catalytic property $[13,14]$. Thanks to its superhydrophilicity, dusts and organic contaminants formed by UV decomposition of oils... etc. are able to be efficiently removed from the surface under rainwater, i.e. under a water flow.

In the aim to synthesize antibacterial and easy-to-clean coatings, the wetting property of magnetron sputtered Ag thin films deposited onto substrates exhibiting various morphologies was studied. Ag was chosen for its well-known broad-spectrum antibacterial ability, excellent biocompatibility and satisfactory stability [15-17]. The idea is to build a twoscale roughness, in order to further the removal of water that is used during the cleaning step in the targeted application.

Magnetron sputter deposition was used among PVD techniques because most of the materials can be efficiently sputtered and many parameters can be varied (input power, gas pressure, target-substrate distance) to control the film properties. For instance, biasing the substrate would allow assisting the film growth by plasma ion bombardment, which is known to enhance the density and lower the roughness. High peak power impulses (HiPIMS) could also be used in order to induce ionization of the sputtered vapor, which could further broaden the accessible range of film characteristics.

In the preliminary study reported in this paper, conventional DC (direct current) magnetron sputtering was used to investigate, first, the growth of Ag on a flat silicon wafer, and second to synthesize $\mathrm{W}$ layers, that were used as textured substrates. W thin films deposited by magnetron sputtering have often been investigated [18-21]. W was chosen in the present work because, depending on the deposition conditions, films with very different features could be obtained, ranging from dense and flat to porous, columnar and rough [22, 23]. Moreover it exhibits good hardness, which is one of the required properties, and has already been deposited in our sputtering apparatus [20]. The influence of the substrate morphology onto the Ag film characteristics was studied by scanning electron microscopy (SEM) and atomic force microscopy (AFM). Contact angle measurements were performed on $\mathrm{Ag}$ on $\mathrm{Si}$ (to study the intrinsic features of $\mathrm{Ag}$ films grown by magnetron sputtering), $\mathrm{W}$ on $\mathrm{Si}$ (to evidence wetting properties introduced by the sublayer) and $\mathrm{Ag}$ on W/Si (final two-scale roughness coatings) in order to evidence the parameters (surface roughness and/or chemistry effect) governing the wetting property.

To our knowledge, it is the first time that a stacking of layers is used to modify the wetting property of an antibacterial deposit in the aim to improve its cleaning efficiency.

\section{Materials and methods}


Ag films and W under-layers were deposited onto Si wafers by DC (direct current) magnetron sputtering of pure Ag (99.99\%) and W (99.99\%) 4" target, respectively. The substrates ( $\mathrm{Si}$ wafers and W/Si) were placed on a heatable-rotating substrate holder $12 \mathrm{~cm}$ away from the target, in a stainless steel vacuum chamber evacuated down to $10^{-4} \mathrm{~Pa}$. Deposition conditions of silver remained unchanged throughout the study: Ar gas pressure was set to $2.5 \mathrm{~Pa}$, and input power to $50 \mathrm{~W}$. The deposition time was varied from $30 \mathrm{~s}$ to 5 min, corresponding to deposited thicknesses from about 3 to $33 \mathrm{~nm}$. For thinnest deposited films, the thickness is calculated from the deposition rate determined on thickest films. In an attempt to investigate a wide range of Ag morphologies, deposition was also carried out at different temperatures: 230 and $400^{\circ} \mathrm{C}$.

In order to synthesize layers with various morphologies, sputtering of $\mathrm{W}$ was carried out at different Ar pressures (from 0.25 to $5 \mathrm{~Pa}$ ) and target-to-substrate distances $(11-12 \mathrm{~cm}$ ). Both parameters (or $\mathrm{P}^{*} \mathrm{~d}$ ) determine the number of collisions that sputtered $\mathrm{W}$ atoms undergo in the gas phase, which plays a role on their kinetic energy as they reach the substrate $[20,22$, 23]. As often reported in literature for PVD techniques, the energy brought by depositing atoms influences the film structure [24-26]. This is especially the case for W, which has been found to form dense smooth films at low pressure and columnar, porous, rough films at high pressure. The input power during W sputter deposition, which is another parameter that could influence the film morphology $[18,20]$, was set to $500 \mathrm{~W}$ in this study. Indeed, the aim of this work was not to perform a parametric study of W growth, but to synthesize $\mathrm{W}$ layers exhibiting a large range of morphologies. This was possible in our experimental configuration with a fixed power. Typical deposition time was $10 \mathrm{~min}$, leading to layers of 300 to $800 \mathrm{~nm}$ thickness. These layers were used as substrates for the deposition of Ag thin films.

After deposition, te the morphology of $\mathrm{Ag}$ on $\mathrm{Si}$, W on $\mathrm{Si}$ and $\mathrm{Ag}$ on W/Si samples were analyzed using a FEG-SEM (Carl Zeiss SMT, Supra-40) and an AFM from Digital Instrument, Nanoscope III using silicon cantilevers $(300 \mathrm{kHz})$. AFM images have been recorded using tapping mode. Only height images are displayed. RMS roughness was estimated using image analysis of the AFM $1 \mu \mathrm{m}^{*} 1 \mu \mathrm{m}$ images. It is important to note that the aim here is to correlate a parameter standing for the surface morphology to the wetting properties of the samples rather than determining a true value of the roughness RMS. X ray diffraction (Brüker D8 Advance, $\lambda_{\mathrm{Cu}}=1.5606 \AA$ ) in $\theta-2 \theta$ configuration was also carried out on $\mathrm{W}$ layers, in order to completely characterize the substrates on which $\mathrm{Ag}$ will be deposited. Static contact angle measurements were performed using a Digidrop apparatus from GBX (http://www.gbxonline.com/). A $2 \mu \mathrm{l}$ distilled water drop was deposited onto the surface and the contact angle was determined by analysis of the recorded images using ImageTool software (http://imagetool.software.informer.com/). Three measurements were done on each sample.

\section{Results and discussion}

\subsection{Ag growth onto Si wafer}

In a first run of experiments, $\mathrm{Ag}$ was sputter deposited onto the flat surface of $\mathrm{Si}$ wafers. Films from 3, 6, 16 to $33 \mathrm{~nm}$ in thickness have been synthesized; corresponding SEM and AFM images are shown on Figure 1.3 and $6 \mathrm{~nm}$ thick thin films (Fig.1a and b) appear 
continuous on both SEM and AFM images, and a tiny fine structure is visible, close to SEM resolution, reason why the $3 \mathrm{~nm}$ thick film could not be imaged by this technique. It seems that the Ag deposit completely wet the Si wafer. On the $16 \mathrm{~nm}$ thick film (Fig.1c), particles of various sizes and shapes are visible, and the $33 \mathrm{~nm}$ thick film is composed of 25-30 nm spherical particles (Fig.1d). Very good agreement is found between SEM and AFM analyses.

From the above observations it appears that a change occurs in the growth mode of silver between $6 \mathrm{~nm}$ and $16 \mathrm{~nm}$ thick films. It turns from the covering of the substrate by a wetting Ag film (2D layer), to the formation of 3D islands. This kind of Stranski-Krastanov mode has already been observed for Ag growth on substrates of different kinds: $\mathrm{Si}$ (001) [27] and $\mathrm{ZrNiCuAl}$ metallic glass [28]. In this second study, 3D islands are detected above $6 \mathrm{ML}$, i.e. for thicknesses above $11 \mathrm{~nm}$, which is in good agreement with our results, since we observed 3D islands for $16 \mathrm{~nm}$ thick film. Jing et al evidenced that 3D islands are composed of several fragments indicating the presence of grain boundaries, which suggests that they are polycrystalline [28]. The same kind of observation can be made on AFM images of both 16 and $33 \mathrm{~nm}$ thick films in the present work in Figure 1.

On $16 \mathrm{~nm}$ thick film (Fig.1c), $100 \mathrm{~nm}$ clusters exist with smaller ones of various sizes and shapes, which is very different from what is seen on the $6 \mathrm{~nm}$ thick film. Moreover, voids seem to appear between smallest clusters, and the roughness that was very low before $(0.6 \mathrm{~nm}$ on 3 and $6 \mathrm{~nm}$ thick films) increases up to $2.1 \mathrm{~nm}$. Clearly the homogeneous 2D layer present on previous films seems to be completely modified. Same kind of morphology has been reported by Polop et al [29] in their study of Ag growth on amorphous silicon in the same range of thickness $(16 \mathrm{~nm})$. This could be explained by the unwetting of the previously formed 2D layer. It has been reported that, in some cases, this 2D layer becomes unstable when the 3D islands start to grow. This has been explained by the fact that some of the $\mathrm{Ag}$ atoms leave the 2D layer and go into the 3D islands, exposing area of the original substrate [27]. In the $33 \mathrm{~nm}$ thick film (Fig.1d), the 2D layer does not exist anymore, the clusters exhibit an intermediate size and form a structure typically obtained when pure 3D island growth occurs like, for example, in the case of Pd growth on silicon [30].

It is important to note that the 2D layer observed at low Ag content seems not to be related to chemical reactivity at the interface since 1 ) the $\mathrm{Si}$ wafer is covered by a stable $2 \mathrm{~nm}$ thick native oxide and 2) Ag is known to have no chemical affinity with Si [29].

Complete study of the growth mode of $\mathrm{Ag}$ is out of the scope of this paper, the aim in the present work being to evidence the morphology of Ag films depending on the thickness and correlate them with the wetting property. Comparison with literature shows that Ag growth occurs in an already reported "pseudo-Stranski-Krastanov" mode. This mode could be very interesting for the targeted property since different morphologies could be obtained: continuous 2D layer or 3D islands. However, analysis of AFM images reveals that the roughness does not vary in a very large range (0.6 to $2.2 \mathrm{~nm}$ ). In an attempt to enlarge this range, depositions have been carried out in various deposition conditions.

Figure 2 shows SEM and AFM images of a $6 \mathrm{~nm}$ thick $\mathrm{Ag}$ film grown at $400^{\circ} \mathrm{C}$. The obtained morphology is completely different from what has been seen at room temperature: clusters of various sizes ranging from 10 to $80 \mathrm{~nm}$ are present and substrate surface is visible 
between them, especially on SEM images. Thus, it seems that when the substrate is heated during the growth, 2D layer is not able to be formed or, that the unwetting phenomenon starts early, i.e. at lower deposited thickness.

Deposition of $33 \mathrm{~nm}$ thick $\mathrm{Ag}$ film was performed at 230 and $400^{\circ} \mathrm{C}$. Results are presented in Figure 3. Large 3D aggregates are formed, which size increases and density decreases with temperature. It is important to note, however, that very small clusters are also visible in addition to big ones: the cluster size distribution appears to be bimodal.

The tendency of Ag films to unwet the substrate and form large 3D islands when heated has already been reported [28]. Kim et al has also evidenced this behavior in their study on the thermal stability of Ag thin films [31]. They investigated the resistivity of Ag films with thicknesses of 35, 69 and $85 \mathrm{~nm}$. They showed that unwetting of the film, i.e. formation of 3D clusters by agglomeration, which induces a sharp increase of the resistivity, occurred at higher temperature for thickest films. They found an agglomeration temperature of $102^{\circ} \mathrm{C}$ for the $35 \mathrm{~nm}$ thick film. This is in quite good agreement with our results, since large aggregates are observed on $33 \mathrm{~nm}$ thick film from $230^{\circ} \mathrm{C}$ deposition temperature (see Fig.3a). However, in the present work, Ag clusters of very small sizes are also present, forming a kind of background on SEM pictures. This is especially visible on the $33 \mathrm{~nm}$ thick film deposited at $400^{\circ} \mathrm{C}$ (see Fig.3b). This difference with Kim's results may be due to the fact that our work does not deal with an annealing process, but with an increase of the deposition temperature. In Kim's case the thermal stability of the film is involved, in ours, the growth mechanism itself is affected. The main result regarding the present study is that very different morphologies were obtained and larger roughnesses were reached.

Contact angle measurements were performed on all synthesized Ag films. Results are presented on the graph of Figure 4 in function of the roughness measured on AFM images. When the roughness is very low, i.e. at small thicknesses, high values are measured, typical of hydrophobic films. A clear trend observed on the figure is a decrease of the contact angle as the roughness rises.

\subsection{Characterization of W layers}

The growth of W on Si by magnetron sputter deposition has widely been investigated and the film microstructure and density are known to vary a lot $[18,21,23]$. The kinetic energy brought by $\mathrm{W}$ atoms at the substrate has been evidenced as the major parameter determining the morphology, for a fixed input power [18]. Sputtered $\mathrm{W}$ atoms lose their kinetic energy by collision with Ar gas atoms in their travel towards the substrate. The number of collisions between Ar and W atoms depends on both the pressure and the distance between the target and the substrate, thus variation of the $\mathrm{P}^{*} \mathrm{~d}$ parameter allows to synthesize $\mathrm{W}$ films with various morphologies. Table 1 presents the experimental parameters used in this work to develop three typical $\mathrm{W}$ films: $\mathrm{W} A, \mathrm{WB}$ and $\mathrm{WC}$ on Si wafer.

Table 1:

Experimental parameters of the typical $\mathrm{W}$ films: $\mathrm{W} A, \mathrm{~W} B$ and $\mathrm{WC}$.

\begin{tabular}{|c|c|c|c|}
\hline \multirow{2}{*}{ W layers on $\mathrm{Si}$} & \multicolumn{3}{|l|}{ Experimental conditions } \\
\hline & Temperature & Pressure* distance (Pa.cm) & Thickness (nm) \\
\hline
\end{tabular}




\begin{tabular}{lllll}
\hline \hline WA & 500 & RT & 3 & 360 \\
WB & 500 & RT & 30 & 700 \\
WC & 500 & RT & 60 & 800
\end{tabular}

SEM plane views and cross sections are given in Figure 5 for typical $\mathrm{W}$ films grown at low and high $\mathrm{P}^{*} \mathrm{~d}$. At low values, for $\mathrm{W} A$ layer (Fig.5a), kinetic energy of the $\mathrm{W}$ atoms is higher, and thus surface diffusion occurs which leads to a dense close-packed structure exhibiting a smooth surface with a roughness value equal to $2.1 \mathrm{~nm}$. On the contrary, at high values (WB and WC layers), when the deposited kinetic energy is low, a porous columnar film is formed, composed of sharp grains at the surface which join together to form kind of islands separated by a deeper void frontier (see Fig.5b and Fig.5c).

AFM analysis was conducted on these W layers, but images have only been successfully obtained on WA (see Fig. 6). It is thought that the kind of needles made of hard W (see Fig. 5c) present on the other W layers could damage the AFM tip and, consequently, prevent from obtaining an image of the surface. This wear mechanism is expected to be less critical on the smooth morphology of WA. On this last layer, lamellar nature of the grains grown at low $\mathrm{P}^{*} \mathrm{~d}$ evidenced by SEM is well observed and AFM images too (Fig.6).

XRD performed on $\mathrm{W} A$ and $\mathrm{W} B$ layers (see Fig.7) shows that the $\beta-\mathrm{W}$ phase is present in both cases, in contrast to a small amount of the $\alpha-\mathrm{W}$ phase which is nevertheless only detected on WA synthesized at the lowest $\mathrm{P} * \mathrm{~d}$ value. Appearance of both phases in sputtered $\mathrm{W}$ thin films has been studied by many authors. $\beta-\mathrm{W}$ phase is a defect phase, usually obtained at high pressure and stabilized by the presence of O contamination [32-34]. It has also been evidenced in $\mathrm{W}$ nanorods elaborated at grazing incidence and high $\mathrm{P} * \mathrm{~d}$ values $[22,23]$. On the contrary, $\alpha-\mathrm{W}$ phase formation is furthered at low pressure, in agreement with its presence in the WA layer. On the XRD patterns, it is interesting to note that the FWHM of the peaks are broader in the case of WC. The average size of the crystallites in WA layer calculated using Scherer formula, is equal to 35 and $29 \mathrm{~nm}$ corresponding respectively to the first two reflections at around $35^{\circ}$ and $40^{\circ}$. For $\mathrm{WC}$ layer, the obtained values are lower: about 7 and $11 \mathrm{~nm}$. Even if diffracting domains cannot be determined from SEM observations, the better crystallinity of WA evidenced by XRD can be correlated to the denser layer composed of larger grains seen on SEM images (Fig.5).

Contact angle measurements performed on these $\mathrm{W}$ layers on silicon have revealed a highly hydrophilic behavior, whatever the morphology (see Fig.9). On some of them, water was so spread that no angle could be measured. In some cases, when the surface was tilted, the water was seen to slide very easily until it was removed from the surface. This sliding behavior could be interesting for cleaning applications. As reported by some authors for hydrophobic surfaces, when a water droplet slides, in addition to roll off, the removal of dirt and soil is promoted [4]. If water completely spread the surface before sliding, the cleaning effect could be enhanced.

\subsection{Ag deposition onto $W$ layers}

\subsubsection{Deposition of Ag at room temperature}


Table 2 presents the notation used to describe the different Ag layers deposited on W/Si substrates according to their thickness and temperature. In this first part, Ag3_RT, Ag6_RT and Ag33_RT were deposited onto WA, WB and WC layers. SEM and AFM images for Ag3_RT and Ag33_RT layers are given in Figure 8. One has to keep in mind that a wetting 2D layer was obtained on Si wafer for a thickness of $3 \mathrm{~nm}$. On SEM image of the Ag3_RT on WA sample (Fig.8a), the fine lamellar structure of the bare WA (see Fig. 5a) is not visible anymore, whereas the main general aspect is still apparent. The same conclusion can be made on the AFM image: lamellae that were clearly evidenced on the original WA layer (see Fig. 6a), appear now covered by particles (Fig. 8a) that are attributed to the Ag deposit. On the two other Ag3_RT samples (Fig.8b and Fig.8c), the structure of the bare W layer is still visible on SEM images, but a close look indicates that the W structure is partly coated by Ag (compare Fig.8b with Fig.5b and Fig.8c with Fig.5c). On AFM images (Fig. 8b and $8 \mathrm{c}$ ), the general appearance of the surface is the same as evidenced by SEM. The islands present on bare WC (Fig. 5c) are particularly well evidenced. It appears that the morphology of $\mathrm{W} B$ and $\mathrm{WC}$ layers impedes the formation of a completely wetting Ag layer, in opposite to what happens on the "flat" WA.

On $33 \mathrm{~nm}$ thick Ag film different conclusions can be drawn (see Fig.8 d-f). First on Ag33_RT on WA, the morphology of the W bare layer has completely disappeared, very fine structure is observed on both SEM and AFM images. Ag film, also evidenced on SEM cross section, seems to hide the W morphology. On Ag33_RT on WB and Ag33_RT on WC images, the general appearance remains, but the $\mathrm{W}$ sharp grains cannot be recognized anymore, they are now decorated by Ag. On the Ag33_RT deposit the obtained morphologies are thus a mixture of Ag and W film features: a two-scale morphology has been built.

Table 2:

Experimental conditions and notations for Ag layers deposited on W layers.

\begin{tabular}{lll}
\hline \multirow{2}{*}{ Ag layers on W } & \multicolumn{2}{l}{ Experimental conditions } \\
\cline { 2 - 3 } & Thickness $(\mathrm{nm})$ & Temperature $\left({ }^{\circ} \mathrm{C}\right)$ \\
\hline \hline Ag3_RT & 3 & RT \\
Ag6_RT & 6 & RT \\
Ag6_400 & 6 & 400 \\
Ag33_RT & 33 & RT \\
Ag33_400 & 33 & 400
\end{tabular}

Contact angle and roughness measurements were performed on all these Ag layers on W/Si samples. On the graph of Figure 9 histograms present contact angles for these samples as well as for bare $\mathrm{W}$ and $\mathrm{Ag}$ layers on Si samples. Tungsten is intrinsically hydrophilic, the smooth WA layer exhibits a contact angle of $65^{\circ}$. When the roughness increases, the hydrophilic character of $\mathrm{W}$ is enhanced (see values for $\mathrm{W} B$ and $\mathrm{WC}$ ), as expected, since it is known that roughness tends to further the wetting property of a chemical element [1]. It is seen on this graph that when the Ag film is thick (Ag33_RT), the wetting property is mainly governed by Ag element: high contact angles are measured. As mentioned above, $\mathrm{Ag}$ on $\mathrm{Si}$ samples are hydrophobic (see Fig. 4). Another result visible on the histograms is that for the same Ag film thickness, the contact angle value is the lowest when the $\mathrm{W}$ layer is the roughest. For instance Ag3_RT layers, contact angle values turn from $93^{\circ}$ on $\mathrm{W} A, 55^{\circ}$ on $\mathrm{W} B$ to $32^{\circ}$ on $\mathrm{WC}$. It can be deduced that the wetting property of the thinnest $\mathrm{Ag}$ deposits (Ag3- 
RT and Ag6_RT) on W/Si is clearly a combination of Ag films and W layers intrinsic properties.

\subsubsection{Deposition of Ag at high temperature}

6nm and 33nm thick Ag films (Ag6_400 and Ag33_400 layers) have also been deposited at $400^{\circ} \mathrm{C}$ onto various W layers. SEM and AFM images are shown on Figure 10. From SEM cross-sections given on Figure 11, it can be checked that the underlying W layer does not evolve during the deposition step at this temperature.

On WA layer the thinnest Ag film (Fig. 10 a) exhibits morphology similar to that obtained on Si wafer, which is not surprising since, as mentioned above, this flat WA layer does not affect the Ag growth mode. Morphology of the Ag6_400 on WC (Fig.10b) on the contrary, is completely different. The general appearance of the bare $\mathrm{W}$ layer is preserved, but, again, sharp grains seem to be decorated by Ag. Some larger clusters are also visible locally. AFM analysis gave clear images and no wear process of the tip took place. This is an indication that $\mathrm{W}$ grains are covered by Ag. Comparison of Fig. 10a and 10b clearly shows that rough WC under-layer induces the growth of smaller grains. Similar trends can be drawn from the images of the thick Ag film: the morphology on WA layer is close to that on silicon (see Fig. 3b), whereas the texture of the $\mathrm{WC}$ under-layer impedes the formation of big Ag grains (Fig.10c and Fig.10d).

The contact angles of all the Ag on W/Si samples are put together in the graph given Figure 12. The same trend is observed than on Si wafer, i.e. the contact angle is the highest when the roughness is the lowest. But on these Ag on W/Si samples the range of contact angle is larger than on $\mathrm{Ag}$ on $\mathrm{Si}$ ones, starting from $106^{\circ}$ down to $17^{\circ}$, in a limited roughness interval. On the Figure 12, green squares correspond to $\mathrm{Ag}$ deposits performed at $400^{\circ} \mathrm{C}$. Working at this temperature allows reaching higher roughness values and very low contact angle values. An interesting result is that some of the Ag films deposited onto rough $\mathrm{W}$ layers exhibit the already described sliding property that could be very useful for cleaning application.

\section{Conclusion}

In this work, Ag thin films were deposited onto flat Si wafers and W layers of various morphologies. Variation of the growth mode and of the final roughness on these textured under-layers was investigated by SEM and AFM. Wetting property of Ag deposit on W/Si samples was compared to that of the bare layers (Ag on $\mathrm{Si}$ and $\mathrm{W}$ on $\mathrm{Si}$ ) and correlated to the roughness measured on AFM images.

Ag on Si films were found hydrophobic, they exhibit contact angles larger than $90^{\circ}$. It was shown that the sharp column structure furthers the intrinsic hydrophilic property of tungsten. On the roughest $\mathrm{W}$ layers a sliding behavior was evidenced.

Depositing a non-continuous Ag film on W layers leads to a wetting property that is a combination of the surface roughness driven by the $\mathrm{W}$ sublayer, and a chemical effect (role of the Ag upper layer). This allows, for the same amount of deposited Ag, to turn from a hydrophobic film to a highly hydrophilic one, by playing with the $\mathrm{W}$ sublayer morphology. 
On the smoothest W layer, the growth of $\mathrm{Ag}$ was found similar to that on $\mathrm{Si}$.

No super-hydrophobic neither super-hydrophilic films were obtained in this work, partly because the variation of roughness and size of the patterns remains in a limited nano-scale range. The aim of this work was thus not to synthesize such surfaces, but to find a

compromise between desired properties. We have shown that the stacking of Ag and W layers allowed to modify the intrinsic wetting property of silver and to synthesize highly hydrophilic sliding Ag surfaces that would further the interaction with bacteria and promote the removal of soil under a water flow.

\section{Acknowledgements}

The authors want to thank Patrick Laffez for XRD analyses and discussions on results. This work was supported by La Région Centre and Europe via European regional development fund (FEDER). 


\section{References}

[1] L. Raibeck, J. Reap, B. Bras, Investigating environmental burdens and benefits of biologically inspired self-cleaning surfaces, CIRP Journal of Manufacturing Science and Technology 1 (2009) 230-236

[2] B. Bhushan, Y. C. Jung, Natural and biomimetic artificial surfaces for superhydrophobicity, self-cleaning, low adhesion, and drag reduction, Progress in Materials Science 56 (2011) 1-108.

[3] D. Oner T. J. McCarthy, Ultrahydrophobic Surfaces. Effects of Topography Length Scales on Wettability, Langmuir 16 (2000) 7777-7782.

[4] L.B.Boinovich, A.M.Emelyanenko, Hydrophobic materials and coatings: principles of design, properties and applications, Russian Chemical Reviews 77 (7)(2008) 583-600.

[5] Y.T. Cheng, D E Rodak, C.A. Wong, C.A. Hayden, Effects of micro- and nano-structures on the self-cleaning behaviour of lotus leaves, Nanotechnology 17 (2006) 1359-1362,

[6] X. Fu, X. He, Fabrication of super-hydrophobic surfaces on aluminum alloy substrates, Applied Surface Science 255 (2008) 1776-1781.

[7] T. Hang, A. Hu, H. Ling, M.Li, D. Mao ,Super-hydrophobic nickel films with micro-nano hierarchical structure prepared by electrodeposition, Applied Surface Science 256 (2010) 2400-2404.

[8] W. Xi, Z. Qiao, C. Zhu, A. Jia, M. Li, The preparation of lotus-like super-hydrophobic copper surfaces by electroplating, Applied Surface Science 255 (2009) 4836-4839.

[9] K. Liu, Y. Tian, L. Jiang, Bio-inspired superoleophobic and smart materials: Design, fabrication and application, Progress in Materials Science 58 (2013) 503-564.

[10] www.gelest.com Hydrophobicity, Hydrophilicity and Silane Surface Modification by Barry Arkles

[11] O.-U. Nimittrakoolchai, S.Supothina, Deposition of organic-based superhydrophobic films for anti-adhesion and self-cleaning applications, Journal of the European Ceramic Society 28 (2008) 947-952.

[12] K. Guan, Relationship between photocatalytic activity, hydrophilicity and self-cleaning effect of TiO2/SiO2 films, Surface \& Coatings Technology 191 (2005) 155-160.

[13] A. Fujishima, X. Zhang, Titanium dioxide photocatalysis: present situation and future approaches, C. R. Chimie 9 (2006) 750-760.

[14] S.-H. Lin, Y.-N. Wu, Y.-C. Lin, Y.-M. Yang, Design and fabrication of antireflective nanoparticulate thin films with superhydrophilic self-cleaning properties on glass substrate, Journal of the Taiwan Institute of Chemical Engineers 42 (2011) 852-859, and references herein.

[15]Y.F. Zheng, B.B. Zhang, B.L. Wang, Y.B. Wang, L. Li, Q.B. Yang, L.S. Cui, Introduction of antibacterial function into biomedical TiNi shape memory alloy by the addition of element Ag, Acta Biomaterialia 7 (2011) 2758-2767. 
[16] M.-K. Kang, S.-K. Moon, J.-S. Kwon, K.-M. Kim, K.-N. KimMaterials Research Bulletin 47 (2012) 2952-2955.

[17] Li Xinping, Li Shengli, Zhang Miaotao, Zhang Wenlong, Li Chuanghong, Evaluations of Antibacterial Activity and Cytotoxicity on Ag Nanoparticles, Rare Metal Materials and Engineering, 2011, 40(2): 0209-0214.

[18] C. Wang, P. Brault, and T. Sauvage, Density measurement of W thin films coating by combination of ion beam analysis and scanning electron microscopy, Eur. Phys. J. Appl.

Phys. 31 (2005) 17-22.

[19] Y. G. Shen, Y. W. Mai, Q. C. Zhang, D. R. McKenzie, W. D. McFall, W. E. McBride, Residual stress, microstructure, and structure of tungsten thin films deposited by magnetron sputtering, Journal of Applied Physics 87(1) (2000) 177-187.

[20] C. Wang, P. Brault, C. Zaepffel, J. Thiault, A. Pineau,T. Sauvage, Deposition and structure of $\mathrm{W}-\mathrm{Cu}$ multilayer coatings by magnetron sputtering, J. Phys. D: Appl. Phys. 36 (2003) 2709-2713.

[21] H.L. Sun, Z.X. Song, D.G. Guo, F. Ma and K.W. Xu, Microstructure and Mechanical Properties of Nanocrystalline Tungsten Thin Films, J. Mater. Sci. Technol., 2010, 26(1), 8792.

[22] T. Karabacak, A. Mallikarjunan, J. P. Singh, D. Ye, G.-Ch. Wang, T.-M. Lu, $\beta$-phase tungsten nanorod formation by oblique-angle sputter deposition, Appl. Phys. Lett., 83(15) 3096-3098.

[23] K. R. Khedir, G. K. Kannarpady, H. Ishihara, J. Wooa, C. Ryerson, A. S. Biris, Morphology control of tungsten nanorods grown by glancing angle RF magnetron sputtering under variable argon pressure and flow rate, Physics Letters A 374 (2010) 4430-4437.

[24] J.A. Thornton, Influence of apparatus geometry and deposition conditions on the structure and topography of thick sputtered coatings, J. Vac. Sci. Technol. 11 (1974) 666.

[25] A. Anders, A structure zone diagram including plasma-based deposition and ion etching, Thin Solid Films 518 (15) (2010) 4087.

[26] I. Petrov, P.B. Barna, L. Hultman, J.E. Greene, Microstructural evolution during film growth J. Vac. Sci. Technol. A 21 (5) (2003) S117.

[27] J. C. Glueckstein, M. M. R. Evans, J. Nogami, Surface unwetting during growth of Ag on Si(001), Physical Review B 54(16) (1996) R11 66-69.

[28] D. Jing, B. Unal, F. Qin, C. Yuen, J.W. Evans, C.J. Jenks D.J. Sordelet P.A. Thiel, Stranski-Krastanov-like growth of an Ag film on a metallic glass, Thin Solid Films 517 (2009) 6486-6492.

[29] C. Polop, C. Rosiepen, S. Bleikamp, R. Drese, J. Mayer, A. Dimyati, T.Michely, The STM view of the initial stages of polycrystalline Ag film formation, New Journal of Physics 9 (2007) 74 1-19. 
[30] P. Brault, A.-L. Thomann, Caroline Andreazza-Vignolle, Percolative growth of palladium ultrathin films deposited by plasma sputtering, Surface Science 406 (1998) L597L602.

[31] H. C. Kim, T. L. Alford, D. R. Allee, Thickness dependence on the thermal stability of silver thin films, Applied Physics Letters 81, 4287 (2002) 4287-4289.

[32] Y.G. Shen, Y.W. Mai, Influences of oxygen on the formation and stability of A15 $\beta$-W thin films, Materials Science and Engineering A284 (2000) 176-183.

[33] I.Djerdj, A.M. Tonejc, A.Tonejc, N.Radic, XRD line profile analysis of tungsten thin films, Vacuum 80 (2005) 151-158.

[34] M. J. O'Keefe, J. T. Grant, Phase transformation of sputter deposited tungsten thin films with A15 structure, J. Appl. Phys. 79 (1996)9134-9141. 
Figure caption

Figure 1: SEM and AFM images of Ag films with various thicknesses deposited on silicon: a) $3 \mathrm{~nm}, \mathrm{~b}) 6 \mathrm{~nm}$, c) $16 \mathrm{~nm}, \mathrm{~d}) 33 \mathrm{~nm}$. Morphology of the $3 \mathrm{~nm}$ thick film is to fine to be observed by SEM.

Figure 2: SEM and AFM images of a $6 \mathrm{~nm}$ thick Ag film grown on $\mathrm{Si}$ at $400^{\circ} \mathrm{C}$.

Figure 3: SEM and AFM images of a $33 \mathrm{~nm}$ thick $\mathrm{Ag}$ film deposited onto $\mathrm{Si}$ at a) $230^{\circ} \mathrm{C}$ and b) $400^{\circ} \mathrm{C}$.

Figure 4: Water contact angle measurements (dots) obtained on Ag on Si films as function of the roughness measured on AFM images. The modeled line (dotted line) is only to guide the eyes.

Figure 5: SEM plane views and cross sections of $\mathrm{W}$ layers used as substrates in the present work: a) $\mathrm{W} A$, b) $\mathrm{WB}$ and c) $\mathrm{W} C$.

Figure 6: AFM images of WA layer: a) $1 \mu \mathrm{m} \times 1 \mu \mathrm{m}$, b) $500 \mathrm{~nm} \times 500 \mathrm{~nm}$.

Figure 7: $\theta-2 \theta$ XRD diffractograms of $\mathrm{W} A$ and $\mathrm{W} C$ layers.

Figure 8: SEM and AFM images of Ag films deposited at room temperature on W layers: a) Ag3_RT on WA, b) Ag3_RT on WB, c) Ag3_RT on WC, d) Ag33_RT on WA, e) Ag33_RT on $\mathrm{W} B, \mathrm{f})$ Ag33_RT on WC.

Figure 9: Water contact angles measured on Ag films deposited on Si wafers and various W layers. Values obtained on bare $\mathrm{W}$ layers are also given.

Figure 10: SEM and AFM images of Ag films deposited at $400^{\circ} \mathrm{C}$ on W layers a) Ag6_400 on $\mathrm{W} A, \mathrm{~b}) \mathrm{Ag6} 6400$ on $\mathrm{WC}$, c) Ag33_400 on WA and d) Ag33_400 on WC.

Figure 11: SEM plane views and cross-sections a) and b) before and c) and d) after deposition of $\mathrm{Ag}$ at $400^{\circ} \mathrm{C}$.

Figure 12: Evolution of the water contact angle with respect to the RMS roughness evaluated by AFM on Ag on W/Si samples. 
Figure 1
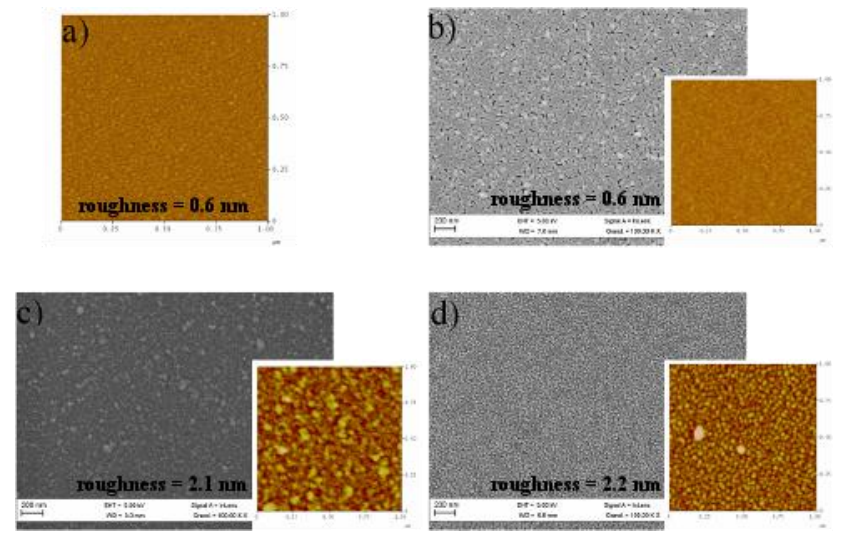

Figure 2

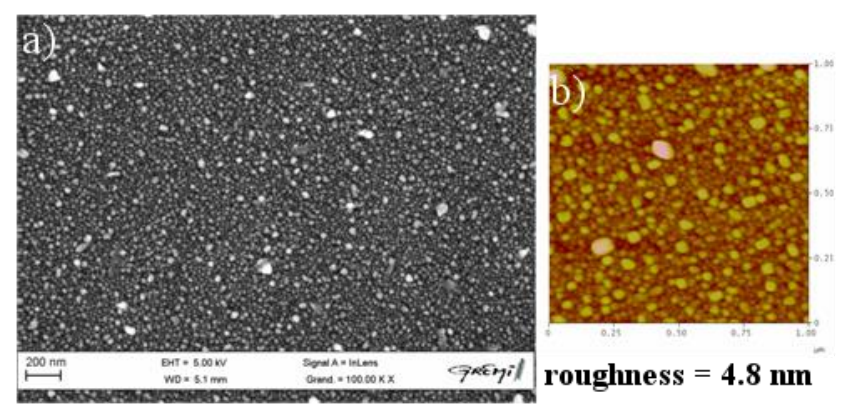

Figure 3

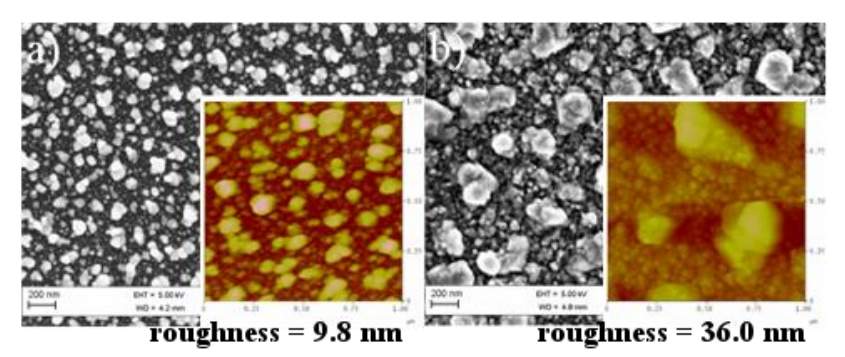


Figure 4

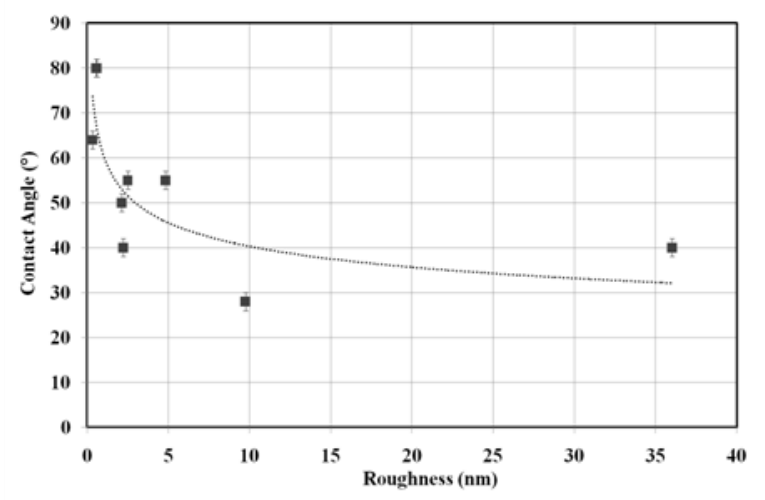

Figure 5

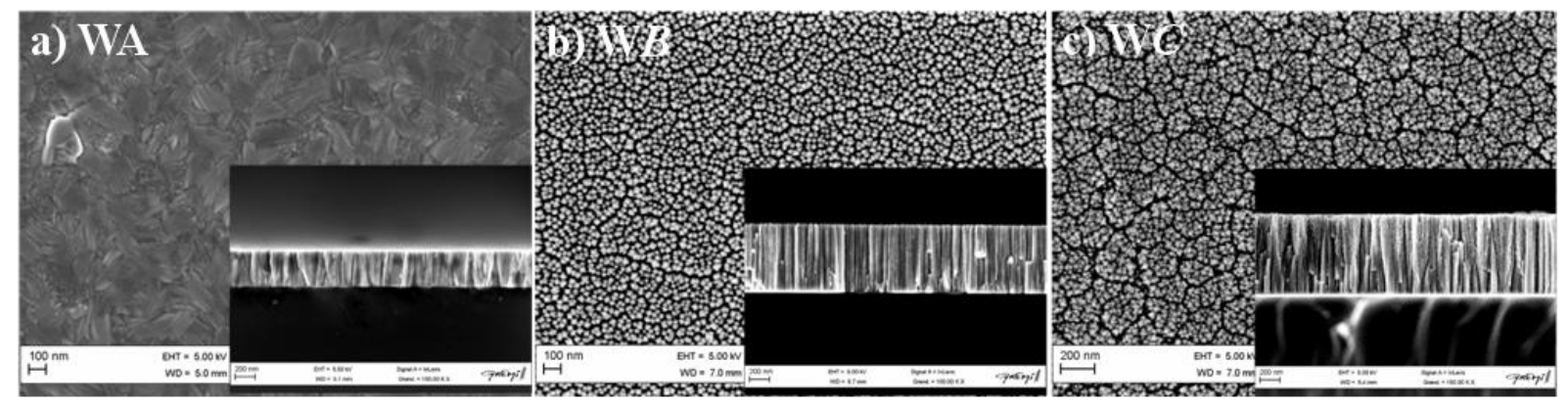

Figure 6

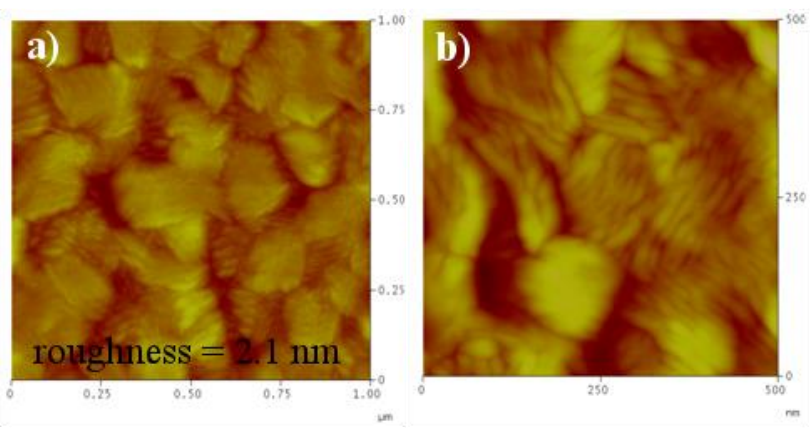


Figure 7

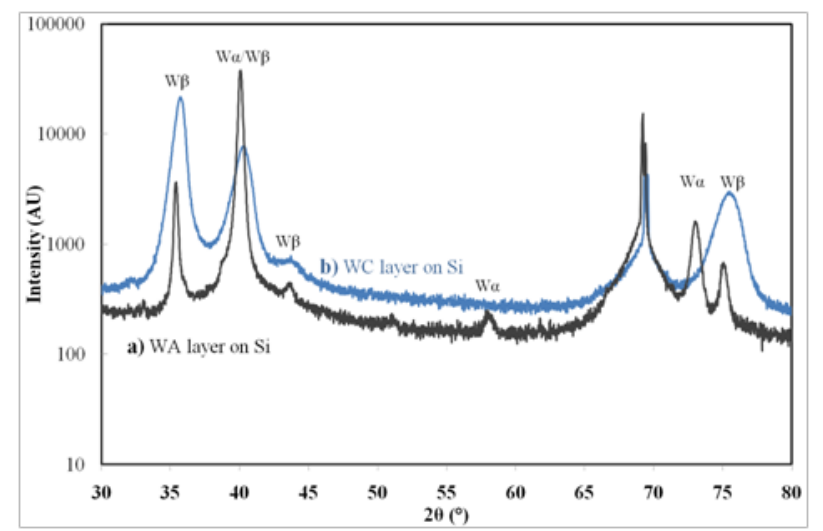

Figure 8
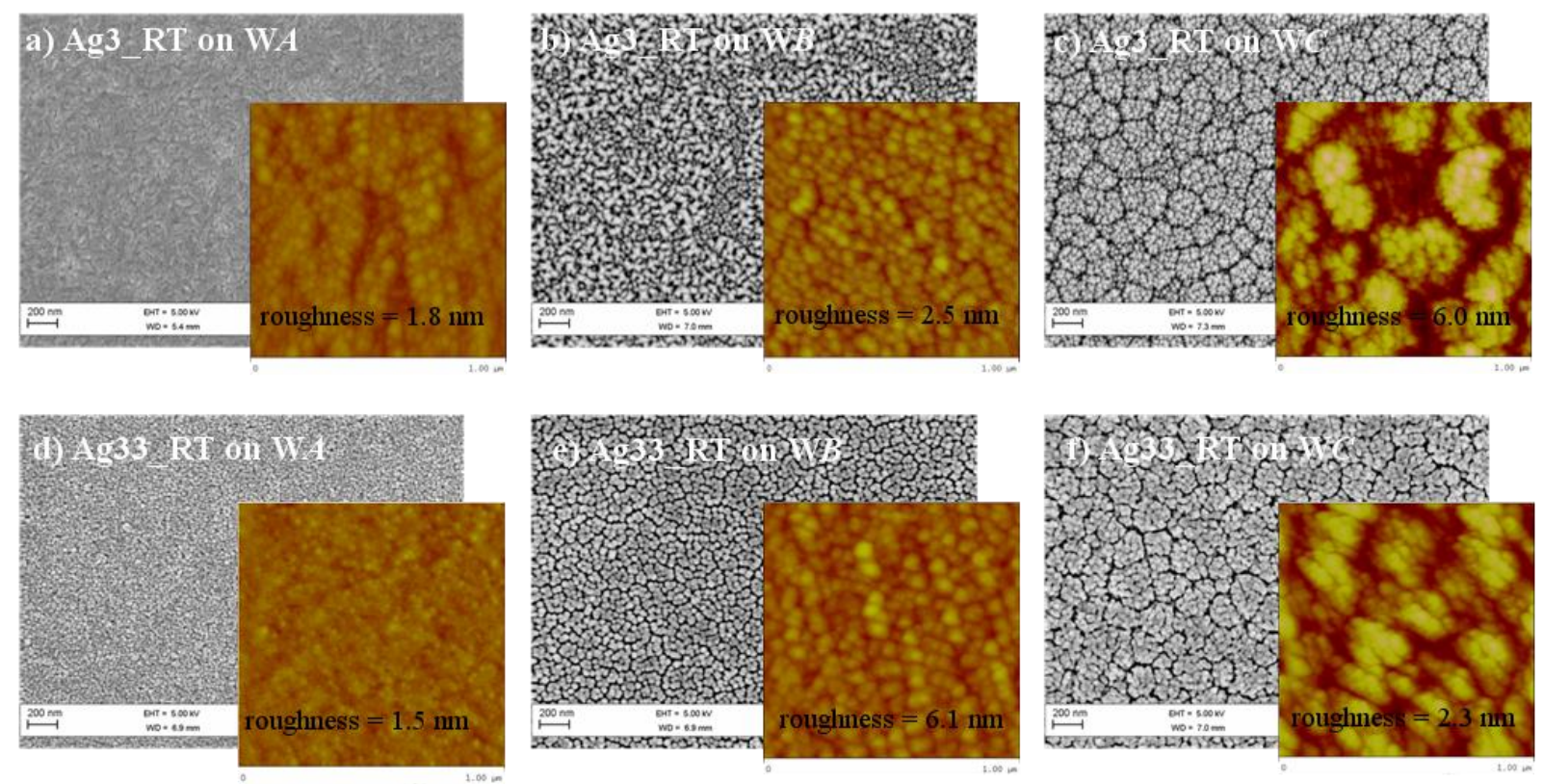
Figure 9

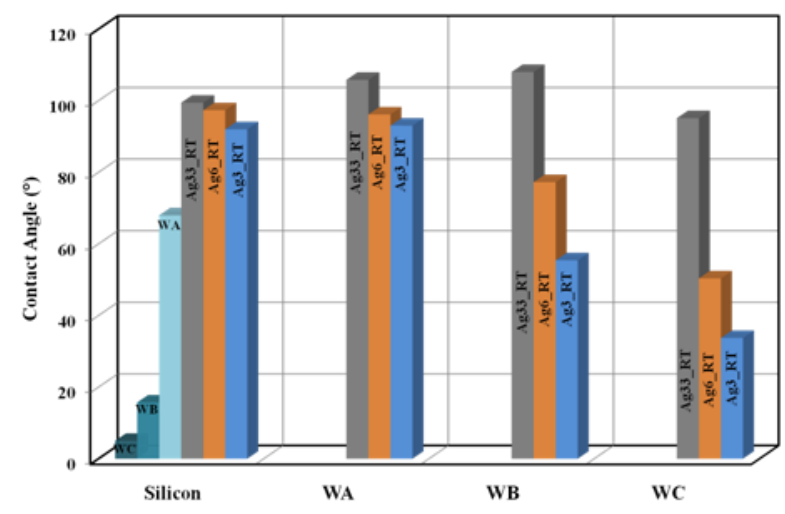

Figure 10
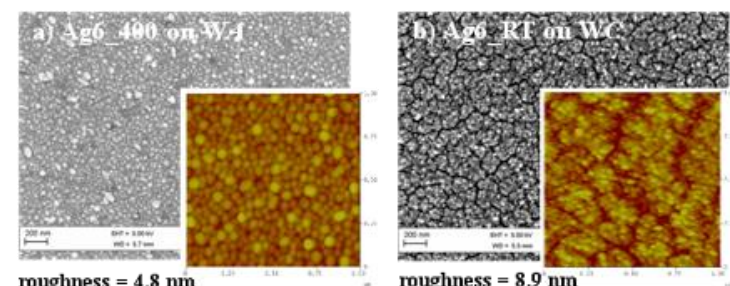

roughness $=4.8 \mathrm{~nm}$

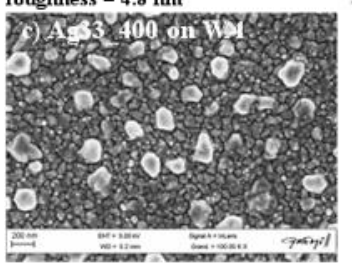

roughness $=8.9 \mathrm{~nm}$

TaA 53500 \%
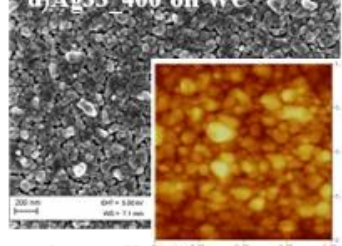

roughness $=11.6 \mathrm{~nm}$ 
Figure 11

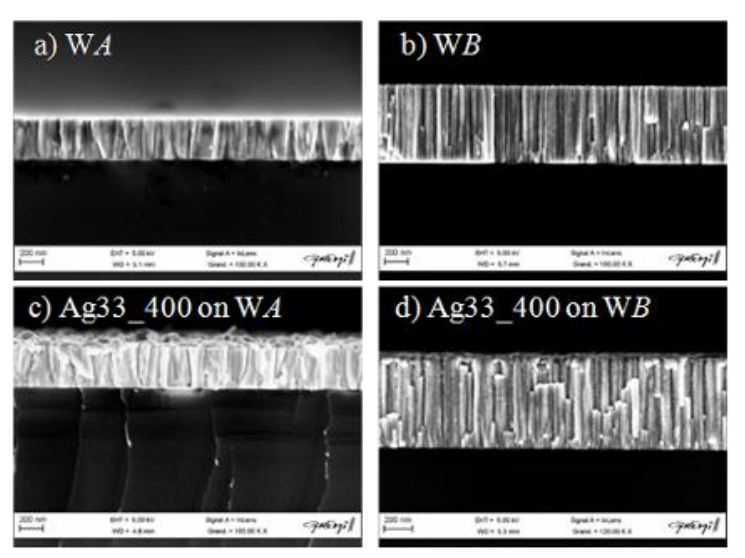

Figure 12

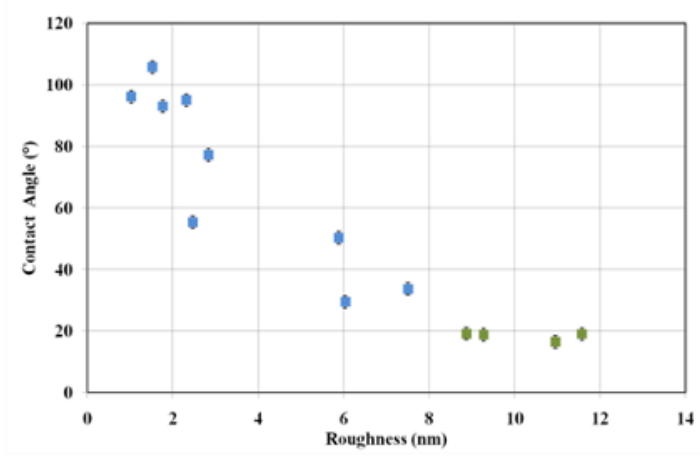

